4Alexander, A. F. O'D., The Planet Saturn Faber and Faber, London, 1962).

${ }^{8}$ Hide, R., J. Atmos. Sci., 26, 841 (1969).

6 Gierasch, P. J., and Stone, P. H., J. Atmos. Sci., 25, 1169 (1968).

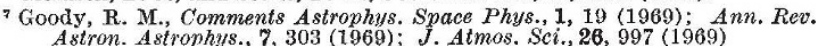

- Stone, P. H., J. Atmos. Sci., 24, 642 (1967).

\section{Twin Terrestrial Impact Craters}

A RECENT article by Mills ${ }^{1}$ has suggested that certain multiple or twin lunar craters may have formed by the slow collapse of a fluidized bed. It was stated that twin astroblemes have not been identified on the Earth and that violent events forming craters, such as meteorite impacts, would be expected to cause considerable destruction of the dividing wall in multiple craters.

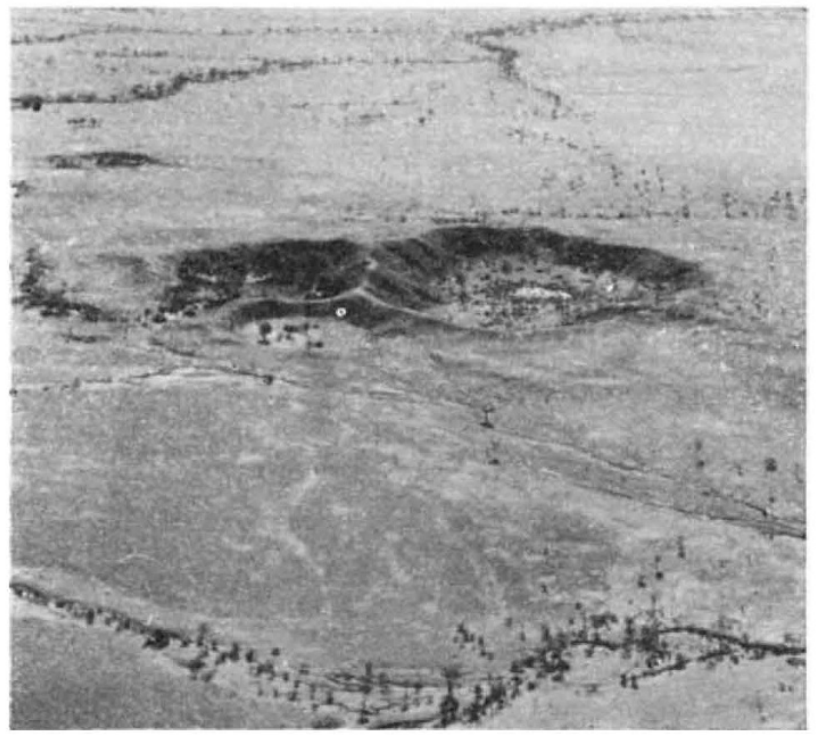
Fig. 1. The three largest craters in the Henbury meteorite crater group
in Central Australia (photo by W. D. E., taken from the east at an altitude of 2,000 feet).

We wish to point out that at least one terrestrial example of multiple impact craters with dividing walls essentially retained does exist. Fig. 1 is an aerial photograph of a portion of the Henbury meteorite crater group in Central Australia. The group of at least twelve impact craters was first described by Alderman'. Craters 6, 7 and 8 as numbered by Alderman are the largost in the group, having maximum rim to rim distances of approximately $74 \mathrm{~m}, 200 \mathrm{~m}$ and $55 \mathrm{~m}$, rospectively. The largest crater is oval in shape and Alderman suggested it may have been formed by two masses landing close together. While it is true that this multiple erater group may have resulted from the break-up of a single body on entry into the Earth's atmosphere, the possibility of a swarm of primary bodies cannot be firmly excluded. This three crater grouping has many features similar to the multiple lunar craters discussod by Mills and is clearly due to meteorite impact. This observation does not invalidate, however, the possibility that several mechanisms may be at work in the formation of the lunar craters.

W. D. Ehmann

J. W. MORGAN

Department of Chemistry,

University of Kentucky,

Lexington, Kentucky 40506.

Received December 15, 1969.

2 Mills, A. A., Nature, 224, 863 (1969).

alderman, A. R., Min. Mag., 28, 19 (1932).

\section{Fireball and Meteorite of April 25, 1969}

WE report a detailed analysis of some 300 observations of the fireball of April 25, 1969, observed from many parts of the British Isles. Appeals in the press and on television led to the collection of many reports, and a request in a special circular of the British Astronomical Association ${ }^{1}$ produced reports from many experienced professional and amateur astronomers. Too many reports have been received to deal with them individually here, and what follows is a general summary.

The track of the fireball projected on the surface of the Earth was determined from observations which recorded the fireball nearly overhead. These were very determinate, fixing the position of the track to within a few kilometres over mid-Wales and Northern Ireland (see Fig. 1). Observations of fireball altitudes from stations some distance from the track were then related to a vertical plane in the position of the track. Although there is some scatter, the reliable observations all fall on a good line (see Fig. 2). From those plots it is clear that the fireball was first sighted at $120 \mathrm{~km}$ height, about $50 \mathrm{~km}$ south of the Dorset coast, moving to the north-north-west. It crossed the south coast at $112 \mathrm{~km}$ just east of Lyme Regis, passing just west of Aberystwyth at $81 \mathrm{~km}$. Crossing the Irish east coast at $44 \mathrm{~km}$ over Dundrum Bay, the fireball passed out over the northern Irish coast at $23 \mathrm{~km}$ over Inishowen Head, to extinguish at $15 \mathrm{~km}$ height $45 \mathrm{~km}$ out into the Atlantic. For a point on the track in midWales, the direction of motion was $332^{\circ} \pm 2^{\circ}$ and angle of descent $9^{\circ} \pm 2^{\circ}$.

Our track confirms the direction of the path of Andrews et $a l . .^{2}$, but we find a height of $64 \mathrm{~km}$ just west of Anglesey instead of the $40 \mathrm{~km}$ quoted by Andrews. Our analysis of reports from southern and central England and south Wales, particularly from the Bristol area, clearly places the track well to the west of that of Meighan and Doughty ${ }^{3}$. Meighan has noted a lack of observations from the Devonshire, Dorset and Somerset areas, but this is not due to the track being farther to the east over southern England as he concluded, but because there was almost complete

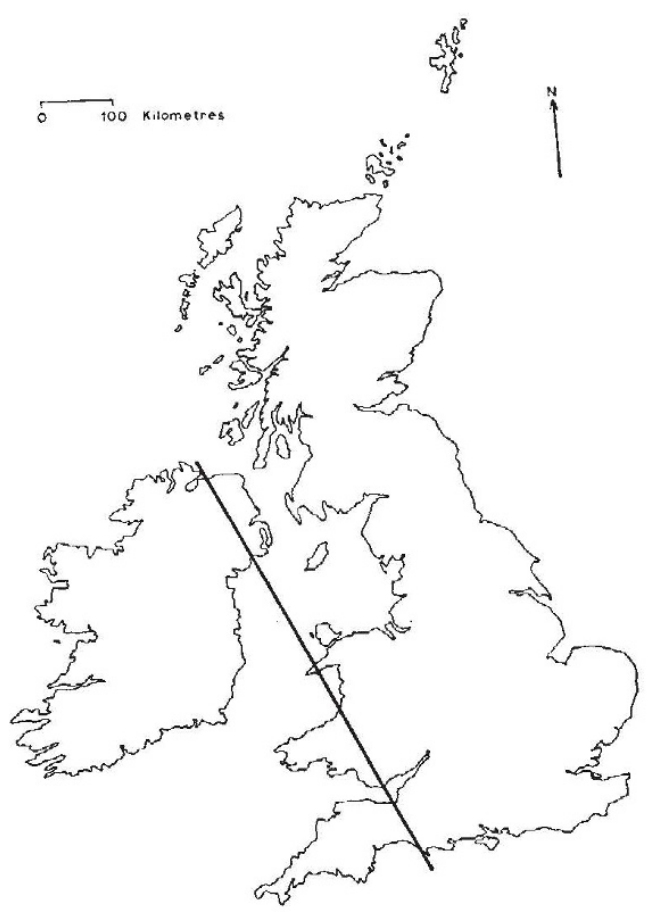

Fig. 1. The track of the fircball and meteorite of April 25, 1969, across the British Isles, deduced from 300 observations. 